Published by LPMP Imperium

Journal homepage: https:/ / ejournal.imperiuminstitute.org/ index.php/ BERDAYA

\title{
Pengembangan Usaha UKM Kedai Kopi Abang Kecamatan Pulogadung Dengan Metode Business M odel Canvas
}

\section{Febriansyah}

Fakultas Bisnis, Institut Teknologi dan Bisnis Kalbis

Email: febriansyah@kalbis.ac.id

\section{ABSTRACT}

This community service program (PKM) is set up to improve the business development of the Kedai Kopi Abang UKM Pulo Gadung District with the Business Model Canvas method. PKM partners are men and women with an age range of 20-30 years. They are the owners and employees of small and medium business units under the name Kedai Kopi Abang. The implementation method used in this PKM activity is training on the topic of the business model canvas as a strategy for creating product differentiation to develop businesses. The results achieved from this activity include: ongoing cooperation with other SME entrepreneurs; SMEs do have differentiated products that are different and superior to similar products owned by competitors; and SMEs can utilize digital marketing channels in developing their businesses primarily in building consumer relationships through Instagram social media

Keywords: business model canvas, SME's

\section{BERDAYA}

\section{9}

\section{Article History}

Received 80ct 2019

Revised 14 Nov 2019

Accepted $28 \mathrm{~N}$ ov 2019

First Published 04 Dec 2019

\section{Reviewing Editor}

Suryani, IAIN

Lhokseumawe

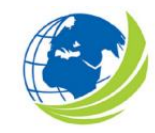

BERDAYA, Vol 1, No.2, December 2019,

pp. 89-96

EISSN XXXX-XXXX

To cite this article: Febriyansyah, F (2019). Pengembangan Usaha UKM Kedai Kopi Abang Kecamatan Pulogadung Dengan Metode Business Model Canvas. BERDAYA : Jurnal Pendidikan dan P engabdian Kepada M asyarakat, 1(2), 89-96

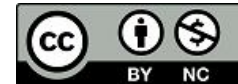

(C) 2019. This open access article is distributed under a Creative Commons Attribution (CC-BY-NC) 4.0 license 


\title{
Pengembangan U saha UKM Kedai Kopi A bang Kecamatan Pulogadung Dengan M etode Business M odel Canvas
}

\author{
Febriansyah \\ Fakultas Bisnis, Institut Teknologi dan Bisnis Kalbis \\ JI. Pulomas Selatan kav. 22 Jakarta Timur, Jakarta, Indonesia \\ Email: febriansyah@kalbis.ac.id
}

\begin{abstract}
ABSTRAK
Program pengabdian kepada masyarakat (PKM) ini dirahkan untuk meningkatkan melakukan pengembangan usaha UKM Kedai Kopi Abang Kecamatan Pulo Gadung dengan Metode Business Model Canvas. Mitra PKM adalah pria dan wanita dengan rentang usia 20-30 tahun. Mereka merupakan pemilik dan pegawai dari unit usaha kecil dan menengah dengan nama Kedai Kopi Abang. Metode pelaksanaan yang digunakan dalam kegiatan PKM ini adalah pelatihan dengan topik business model canvas sebagai strategi penciptaan diferensiasi produk untuk mengembangkan usaha. Hasil yang dicapai dari kegiatan ini antara lain: kerjasama berkelanjutan dengan pelaku usaha UKM lain-nya; pelaku UKM memiliki produk yang memiliki diferensiasi sehingga berbeda dan unggul dari produk sejenis yang dimiliki competitor; dan pelaku UKM dapat memanfaatkan saluran pemasaran digital dalam mengembangkan usahanya utamanya dalam membangun hubungan konsumen melalui media sosial instagram.
\end{abstract}

Kata Kunci : business model canvas, UMKM

\section{PENDAHULUAN}

Perubahan perekomian dunia yang cepat sebagai bagian dari arus globalisasi menyebabkan persaingan yang ketat sehingga diperlukan daya saing yang tinggi agar usaha kecil menengah (UKM) Indonesia mampu bertahan dalam persaingan. Salah satu cara untuk meningkatkan daya saing UKM adalah dengan melakukan diferensiasi produk. Diferensiasi produk adalah semua kegiatan yang dilakukan seorang pengusaha atau pelaku pasar untuk menciptakan sebuah perbedaan yang bertujuan memberikan nilai lebih kepada para konsumen. Diferensiasi dapat dilakukan dengan menciptakan produk yang berbeda, memberikan pelayanan yang berbeda, atau menciptakan citra produk yang unik dan berbeda dari pesaing lain-nya. Keuntungan yang diperoleh UKM dari strategi diferensiasi diantaranya produk jadi lebih mudah diingat konsumen, punya keunggulan secara relatif dari kompetitor, harga jual produk lebih tinggi, mengatasi kejenuhan pasar dan membantu terciptanya citra produk. Namun, masalahnya tidak sedikit dari pelaku UKM lokal yang gagal meraih antuasias pasar karena produknya dinilai kurang unik atau dirasa bukan dari kreasi yang orisinal (Yustiani, 2019). Beberapa UKM masih bingung dalam menerapkan atau mengaplikasikan konsep dari menciptakan diferensiasi. Padahal jika saja mereka mau menerapkan dan mengaplikasikan dengan baik akan membantu bisnis mereka menjadi lebih berkembang dan maju.

Diferensiasi produk yang didasarkan value propositions yang diberikan kepada customer segment sebagai media membedakan diri dengan kompetitor. Value proposition dan customer segment adalah bagian dari sembilan elemen kanvas model bisnis yang populer digunakan perusahaan sebagai backbone strateginya. Kanvas model bisnis yang diciptakan Alexander Osterwalder memiliki keunggulan menjelaskan implementasi strategi perusahaan secara 
sederhana dan tepat sehingga perusahaan dapat mengetahui apakah mereka berada di jalur yang tepat (Wilza, 2017). Dengan mempertimbangkan kondisi di atas, tim PKM Institut Teknologi dan Bisnis Kalbis, melakukan kegiatan Pengabdian kepada Masyarakat (PKM) dengan yang bertujuan untuk melakukan pengembangan usaha UKM Kedai Kopi Abang Kecamatan Pulo Gadung dengan Metode Business Model Canvas.

\section{Persoalan M itra}

Kedai Kopi Abang adalah bisnis tempat makan yang berfokus menjual kopi, meski juga menyediakan menu makanan, namun yang ditonjolkan adalah produk kopinya. Bisnis ini berdiri sejak tahun 2018 yang Ialu, tepatnya di bulan Juni, dan didirikan oleh Reynaldi Aditya Ramadhan (pemilik usaha). Berawal dari hobi meminum kopi, Reynaldi memutuskan untuk mencoba berwirausaha pada minuman favoritnya tersebut. Kedai kopi berkembang sangat pesat di Jakarta, dari observasi yang dilakukan tim PKM Kalbis Institute, kedai kopi abang belum memberikan diferensiasi produk yang membedakannya dan menjadikannya unggul dibandingkan kedai kopi lain-nya. Pada dasarnya pengenalan dan edukasi tentang diferensiasi perlu dilakukan kepada para pelaku usaha UKM dengan cara pelatihan dan pembimbingan, yang diharapkan dapat menambah daya saing UKM.

Berdasarkan kondisi tersebut, maka dilakukan kegiatan PKM untuk melakukan upaya pengembangan usaha mitra UKM dengan upaya peningkatan value preposition, channel dan customer relationship dengan memperhatikan customer segment dari mitra PKM sebagai strategi dalam upaya meningkatkan dan mengembangkan usaha Kedai Kopi Abang selaku mitra PKM. Berdasarkan observasi yang telah dilakukan dan wawancara dengan pemilik usaha, Reynaldi Aditya Ramadhan, berikut adalah beberapa persoalan yang dihadapi oleh UKM Kedai Kopi A bang:

1. Belum memiliki diferensiasi produk yang menonjol

2. Belum memiliki channel promosi dan penjualan selain pada kedai fisiknya.

3. Belum melengkapi kelengkapan identitas produk.

4. Desain kemasan produk dan penunjang produk lain-nya baru seadanya.

5. Belum menerapkan promosi-promosi menarik untuk menarik pelanggan baru atau mempertahankan loyalitas pelanggan lama.

\section{MATERI DAN METODE}

\section{M etode Pelaksanaan}

Metode pelaksanaan yang digunakan dalam kegiatan PKM ini adalah pelatihan dengan topik business model canvas sebagai strategi penciptaan diferensiasi produk untuk mengembangkan usaha. Berdasarkan permasalahan yang telah dipaparkan sebelumnya, maka solusi yang coba dibuat adalah dengan memberikan program pelatihan business model canvas dalam menjembatani gap diantara adanya kebutuhan pengembangan value produk untuk pengembangan usaha dan tuntutan mengurus operasional bisnis sehari-hari. Pelatihan tersebut meliputi rangkaian materi sebagai berikut, yaitu: Pelatihan business model canvas sebagai dasar teoritis; dan Diskusi Pengembangan Value Preposition, Channel dan Customer Relationship antara Tim PKM dan Mitra.

\section{Lokasi dan Waktu Pelaksanaan}


Mitra adalah usaha kecil dan menengah (UKM) yang menjalankan usaha di bidang kuliner dengan omset per-tahunnya dibawah 2,5 Milyar Rupiah sesuai dengan definisi yang dinyatakan pada Pasal 6 Undang-Undang Republik Indonesia No.20 Tahun 2008 tentang UMKM. Mie Ayam 15 buka setiap hari mulai pukul 08:00-19:30 dan berlokasi di JI. Mayor Oking No. 23 RT. 003/ RW. 01, Margahayu, Bekasi Timur, Bekasi, Jawa Barat, 17113, Indonesia. Jumlah UKM yang menjadi mitra dalam program pengabdian kepada masyarakat (PKM) ini yaitu satu unit UKM, yaitu Kedai Kopi Abang yang akan coba ditingkatkan daya saingnya oleh Tim PKM dari Kalbis Institute melalui penciptaan diferensiasi produk dengan menggunakan metode business model canvas. Kegiatan dilaksanakan selama tiga bulan, yaitu dimulai dari bulan Februari 2019 sampai dengan A pril 2019.

\section{Evaluasi Kegiatan}

Setelah proses pelaksanaan diadakan evaluasi untuk melihat apakah pelatihan yang diberikan memiliki indikator keberhasilan. Evaluasi yang dilakukan adalah dengan menerima feedback dari pihak yang menjadi mitra kami.

Indikator Keberhasilan

Ukuran indikator keberhasilan suatu pelatihan bisa dilihat dari tujuan awal dilakukannya pelatihan, yaitu penambahan value produk untuk pengembangan usaha mitra. Indikator tersebut berhasil dilakukan seperti terlihat pada gambar-gambar di bawah ini:

Pertama, tambahan value preposition meliputi : Pembuatan logo sebagai identitas produk, Pembuatan desain kemasan produk: dan pembuatan desain seragam usaha:
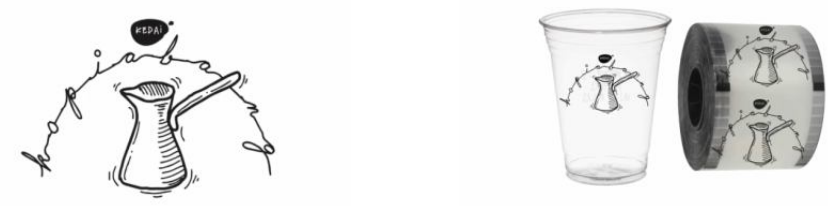

Gambar 1. Tambahan value preposition

Sumber: dokumentasi tim pelaksana (2019)
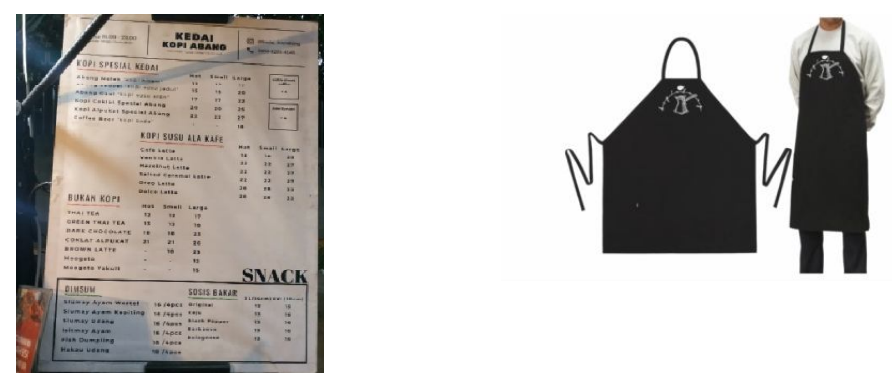

Kedua, tambahan channel promosi dan penjualan meliputi pembuatan banner produk, pembuatan plank toko, dan pembuatan akun istagram. 

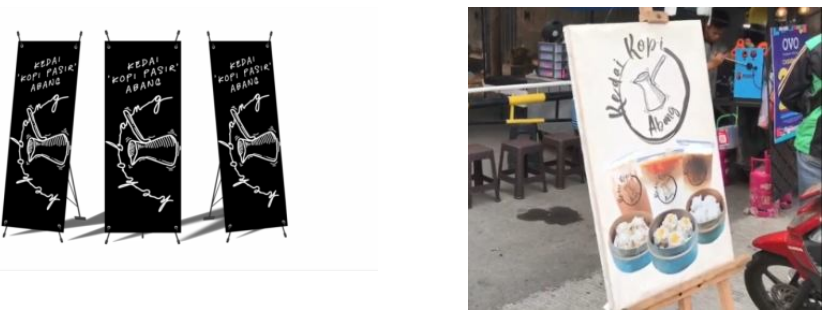

Gambar 2. Tambahan

channel promotion

Sumber: dokumentasi tim pelaksana (2019)

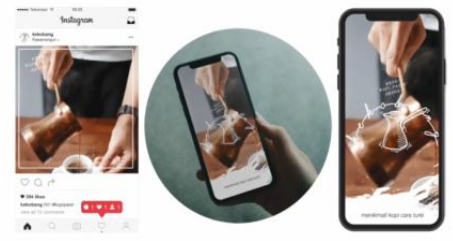

HASIL DAN PEMBAHASAN

\section{Perencanaan kegiatan}

Rapat Persiapan

Pada hari Rabu, 27 Februari 2019 diadakan rapat persiapan untuk membahas perencanaan terkait dengan pelaksanaan PKM. Dalam rapat ini ditentukan lokasi serta waktu observasi yaitu tanggal 13 Maret 2019 dengan objek PKM adalah pelaku UKM di Jakarta Timur, tepatnya di Jl. Tawes Rt3/Rw.7, Pulo Gadung, Jakarta Timur.

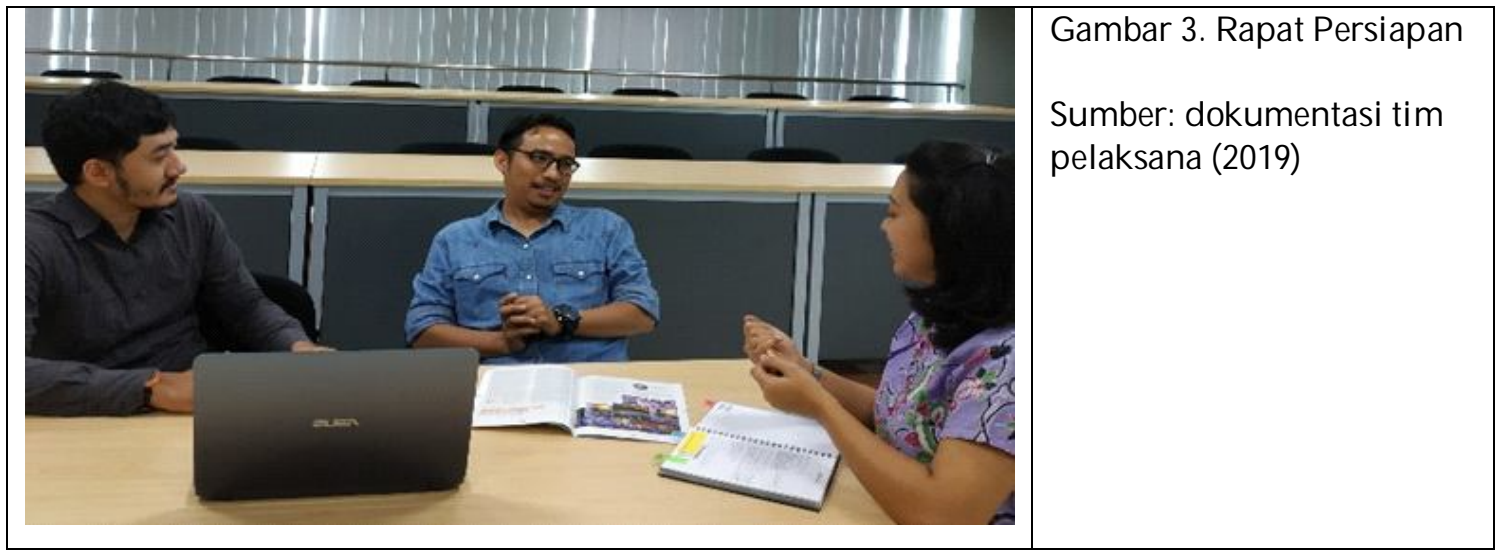

\section{Observasi Mitra PKM}

Pada hari Rabu, 13 Maret 2019 dilaksanakan observasi mitra PKM, bertemu dengan pelaku usaha UKM, yaitu Bapak Reynaldi selaku pemilik Kedai kopi abang, pelaku usaha kuliner. 


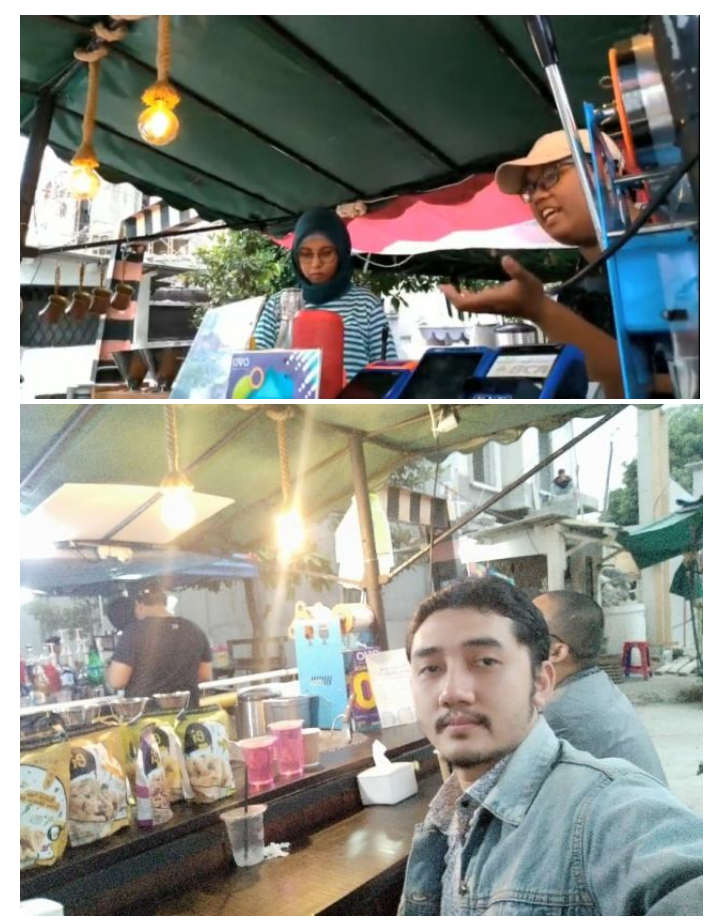

Gambar 4. Observasi ke mitra

Sumber: dokumentasi tim pelaksana (2018)

\section{Rapat Persiapan 2 (D iskusi Solusi \& Pembuatan Materi)}

Pada hari Senin, 25 Maret 2019 telah dilaksanakan rapat persiapan ke-2 (dua) untuk membahas permasalahan yang dihadapi mitra dan solusi yang dapat ditawarkan kepada mitra dan materi yang akan disampaikan kepada mitra.

\section{Finalisasi Materi}

Hari Rabu tanggal 24 April 2019 dilakukan pengecekan materi PKM dan finalisasi materi untuk memastikan semua kebutuhan untuk pelaksanaan PKM sudah terpenuhi.

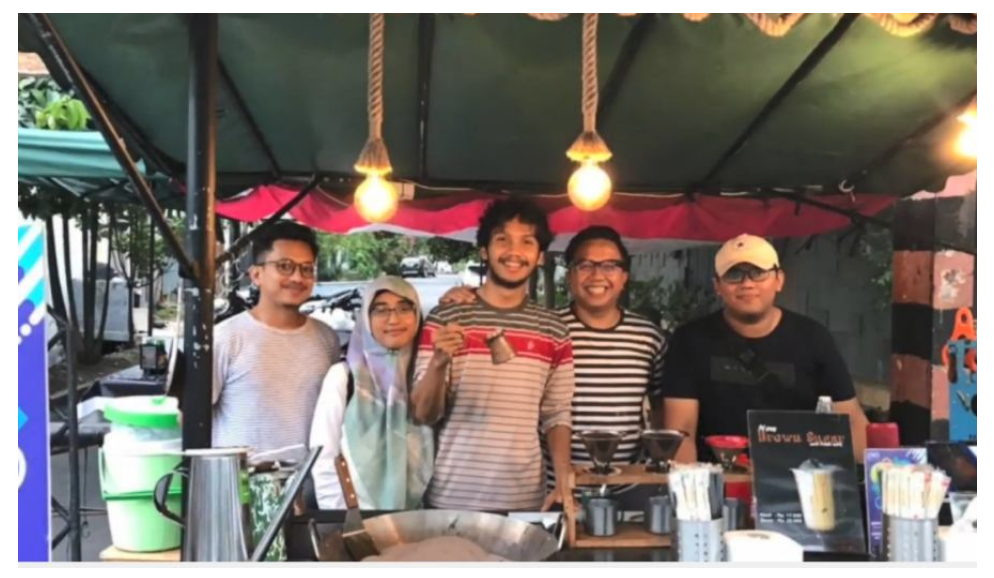

Gambar 5. Pelaksanaan kegiatan

Sumber: dokumentasi tim pelaksana (2019) 
Febriansyah, $\mathrm{F}$

UM KM business model canvas

\section{Pelaksanaan Kegiatan}

Pada tanggal 17 Januari 2019, dilaksanakan acara PKM kepada pelaku usaha UKM Mie A yam 15 yang berlokasi di Kota Bekasi. Penyampaian materi terbagi ke dalam 3 sesi, yaitu pengenal produk digital bagi UKM, pelatihan dan demonstrasi pembuatan jejak digital dan pendampingan pembuatan jejak digital bagi UKM mitra sebagai sarana pemasaran dan pusat informasi toko.

\section{KESIM PULAN}

Dengan pelatihan ini manfaat yang diharapkan akan diperoleh diantaranya:

a. Kerjasama berkelanjutan dengan pelaku usaha UKM lain-nya.

b. Pelaku UKM memiliki produk yang memiliki diferensiasi sehingga berbeda dan unggul dari produk sejenis yang dimiliki kompetitor.

c. Pelaku UKM dapat memanfaatkan saluran pemasaran digital dalam mengembangkan usahanya utamanya dalam membangun hubungan konsumen melalui media sosial instagram.

\section{Usulan Kegiatan yang Dapat Dilanjutkan}

Proses pelaksanaan PKM diharapkan dapat berlanjut lagi dengan terus memonitor kegiatan yang sudah berjalan, dengan selalu didukung oleh motivasi dan pelatihan untuk pemahaman target serta peningkatan kualitas jasa dan produk dari pelaku UKM tersebut.

\section{About Author}

Febriansyah adalah dosen Fakultas Bisnis, Institut Teknologi dan Bisnis Kalbis, Jakarta. Penulis dapat dihubungi di alamat email: febriansyah@kal bis.ac.id

\section{FUNDING}

Kegiatan ini merupakan bagian dari program Pengabdian Kepada Masyarakat yang didanai oleh Institut Teknol ogi dan Bisnis Kal bis tahun 2018-2019

\section{COM PETING INTERESTS}

Tidak ada konflik kepentingan untuk diungkapkan. 
This page intention to blank.. 